\title{
The Impact of Community-Based Outreach on Psychological Distress and Victim Safety in Women Exposed to Intimate Partner Abuse
}

\author{
Anne P. DePrince \\ University of Denver \\ Joanne Belknap and Susan Buckingham
University of Colorado Boulder
}

\author{
Jennifer Labus \\ University of California Los Angeles \\ Angela Gover \\ University of Colorado Denver
}

\begin{abstract}
Objective: Using a longitudinal, randomized controlled trial, this study assessed the impact of a community-based outreach versus a more traditional criminal justice system-based referral program on women's distress and safety following police-reported intimate partner abuse (IPA). Method: Women ( $N=236$ women) with police-reported IPA were randomly assigned to 1 of 2 interdisciplinary community-coordinated response program conditions: Outreach (community-based victim advocate outreach) or Referral (criminal justice system-based victim advocate referrals to community-based agencies). Participants were interviewed 3 times over a 1-year period: within 26 (median) days of police-reported IPA, 6 months later, and 12 months later. Primary outcome measures included posttraumatic stress disorder and depression symptom severity (Posttraumatic Stress Diagnostic Scale; Beck Depression Inventory-II), fear appraisals (Trauma Appraisal Questionnaire), IPA revictimization (Revised Conflict Tactics Scale), and readiness to leave the relationship with the abuser. Results: One year after the initial interview, women in the Outreach condition reported decreased PTSD and depression symptom severity and fear compared with women in the Referral condition. Although both conditions were unrelated to revictimization in the follow-up year, women in the Outreach condition reported greater readiness to leave the abuser and rated services as more helpful than women in the Referral condition. Conclusions: This is one of the first studies to examine community-based outreach in the context of an interdisciplinary community coordinated response to police-reported IPA. The findings suggest that community-based outreach by victim advocates results in decreased distress levels, greater readiness to leave abusive relationships, and greater perceived helpfulness of services relative to system-based referrals.
\end{abstract}

Keywords: intimate partner abuse, coordinated community response, PTSD, depression

A considerable amount of research documents the significant prevalence and scope of intimate partner abuse (IPA) experienced by women (e.g., Rennison \& Welchans, 2000; Tjaden \& Thoennes, 2000). ${ }^{1}$ IPA is linked to serious forms of psychological distress as well as ongoing danger in relationships. In terms of psychological distress, both posttraumatic stress disorder (PTSD) and depression symptoms have been well documented in IPA victims (e.g., R. Campbell, Greeson, Bybee, \& Raja, 2008; Cattaneo \& Goodman, 2010; Coker et al., 2002; Johnson, Zlotnick, \& Perez, 2008; Krause, Kaltman, Goodman, \& Dutton, 2006, 2008; Mechanic, Weaver, \& Resick, 2008). In addition, a handful of studies point to high levels of fear among abused women (Cattaneo \& Goodman,
This article was published Online First February 13, 2012.

Anne P. DePrince, Department of Psychology, University of Denver; Jennifer Labus, Department of Psychiatry and Biobehavioral Sciences, Semel Institute for Neuroscience and Human Behavior, and Oppenheimer Family Center for Neurobiology of Stress, University of California Los Angeles; Joanne Belknap, Department of Sociology, University of Colorado Boulder; Susan Buckingham, Department of Geological Sciences, University of Colorado Boulder; Angela Gover, School of Public Affairs, University of Colorado Denver.

This project was funded by National Institute of Justice Office of Justice Programs, United States Department of Justice Award 2007-WG-BX-0002 to Anne P. DePrince. The opinions, findings, and conclusions or recommendations expressed in this report are those of the authors and do not necessarily reflect those of the Department of Justice or the National Institute of Justice.

Thank you to our study partners, including the Denver District Attorney's Office, City Attorney's Office, Denver Police Department Victim
Assistance Unite, Denver Domestic Violence Coordinating Council, SafeHouse Denver, Project Safeguard, AMEND, and the Triage Steering Committee. Thank you to the Traumatic Stress Studies Group, particularly Melody Combs, Claire Hebenstreit, Ryan Matlow, Courtney Mitchell, Annarheen Pineda, and Jane Sundermann. Finally, thank you to the women who trusted us with their stories over the year during which we were privileged to get to know them.

Correspondence concerning this article should be addressed to Anne P. DePrince, Department of Psychology, 2155 S. Race Street, Denver, CO 80208. E-mail: adeprinc@du.edu

\footnotetext{
${ }^{1}$ Abuse by intimate partners can include physical and nonphysical abuse and is increasingly recognized to include physical, sexual, psychological, and stalking abuse. Given that some of these are not violent per se, we use the term intimate partner abuse (IPA) instead of intimate partner violence.
} 
2010; Fanslow \& Robinson, 2010). Because fear is linked to both PTSD and depression symptoms (e.g., DePrince, Zurbriggen, Chu, \& Smart, 2010), addressing fear as well as PTSD and depression symptoms following IPA is critical to women's psychological health.

Unfortunately, many relationships continue to be dangerous for women exposed to IPA because of high rates of revictimization (e.g., Cattaneo \& Goodman, 2005; Krause et al., 2006, 2008; Robinson \& Tregidga, 2007), which is associated with worse PTSD and depression symptoms (Classen et al., 2005; DePrince, 2005; Krause et al., 2006, 2008). Although the question of whether mental health symptoms contribute to or are consequences of revictimization remains unclear (Classen et al., 2005), links between the two make revictimization a critical consideration in interventions. Importantly, victims cannot control whether their abusers continue to engage in abusive behaviors; thus, interventions should also affect domains in which women can have more control, such as victims' own reasoning regarding staying/leaving. Applications of the transtheoretical model of change to IPA have illustrated that women vary in their readiness to leave abusive partners (Shurman \& Rodriguez, 2006); therefore, interventions that affect readiness to leave may be important to victim safety considerations.

In light of IPA victims' psychological and safety needs, researchers and practitioners have pointed to the urgent need for victim-service providers to make outreach to victims. A handful of studies have now evaluated victim outreach from battered women's shelters (e.g., Bybee \& Sullivan, 2002, 2005; Sullivan \& Bybee, 1999; Sullivan, Bybee, \& Allen, 2002) or emergency rooms and health clinics (e.g., Gillum, Sun, \& Woods, 2009; Kendall et al., 2009), demonstrating some positive effects on women's well-being (e.g., revictimization, safety behaviors, social support). Although promising, these evaluations have been limited to women already using shelter/medical services, many of whom tend to be disproportionately economically marginalized (Cattaneo \& DeLoveh, 2008).

\section{Challenges for Victims When IPA is Reported to Law Enforcement}

When IPA is reported to law enforcement, victims find themselves situated in the criminal justice system, which focuses on the legal case, rather than psychosocial needs. In the aftermath of the incident, criminal justice system-based advocates (hereafter referred to as system-based advocates) are often the first to be in contact with victims. As criminal justice personnel housed in police departments and/or prosecuting attorneys' offices, systembased advocates are subject to disclosure in legal cases and cannot offer women confidentiality during their contacts. Therefore, women may be hesitant to disclose details (e.g., regarding psychological needs) or ask for support when speaking with system-based advocates, because that information will be subject to disclosure to the defense. To connect women with confidential services that address psychosocial needs, system-based advocates have to make referrals to community-based agencies.

Women face many challenges when trying to find appropriate confidential services following police-reported IPA. For example, increases in economic strain (e.g., transitions in housing, economic problems caused by partner's arrest) and demands on women's time (e.g., additional caregiving and/or job responsibilities caused by partner's arrest) may result in practical barriers (e.g., lack of access to a computer) that hamper women's efforts to seek out resources. In addition, cognitive aspects of common posttraumatic responses (e.g., problems with memory) may make organizing and initiating efforts to find resources difficult. Further, many IPA victims have been isolated by perpetrators, leaving them with impoverished social support systems (Sullivan \& Bybee, 1999) and feelings of alienation (DePrince, Chu, \& Pineda, 2011) following IPA that make initiating requests for help difficult. Finally, women may experience obstacles navigating the range of IPA services available in many communities to identify the services most appropriate to her specific case and needs (e.g., counseling vs. legal advocacy).

\section{Community-Coordinated Response (CCR) Programs}

Given the psychosocial needs of and challenges facing IPA victims (particularly following police-reported IPA), researchers and practitioners have increasingly called for the development and evaluation of CCR programs that provide victim advocacy to a broad base of victims (e.g., Allen, Bybee, \& Sullivan, 2004; Fanslow \& Robinson, 2010; Goodman \& Epstein, 2005). CCR programs involve collaboration between community-based (e.g., shelters and legal advocacy programs) and criminal justice systembased (e.g., prosecuting attorney and police) agencies to coordinate victim advocacy for IPA intervention and prevention (Klevens, Baker, Shelley, \& Ingram, 2008). Despite the need to coordinate responses to address victim safety and psychological well-being, most CCR programs have been geared more toward responding to abusers than victims (Goodman \& Epstein, 2005). Given involvement of both criminal justice and community-based agencies, CCR programs are well positioned to respond to the needs of victims following police-reported IPA, although research on the impact of victim advocacy within CCRs on victims is noticeably lacking.

CCR programs that involve outreach directly to victims from community-based (rather than system-based) advocates may be particularly well-poised to mitigate deleterious IPA psychological and safety outcomes. By making outreach directly to victims, community-based agencies remove barriers that might otherwise impede women from seeking out community-based services to address psychosocial needs. Further, the high level of coordination involved in CCR programs means that community-based agencies can be selected to outreach to victims based on specific psychosocial needs. Matching services with victim needs at the point of outreach should lead to better service provision, with resulting gains in psychological symptoms and safety. Further, the process of finding resources should be less stressful (e.g., women do not have to retell their stories as they seek out an agency that meets their needs), which may also reduce distress. Outreach might be particularly important to women who are oppressed or marginalized by life circumstances beyond the IPA itself (e.g., socioeconomic status, physical dependence on the offender) that otherwise add barriers to seeking out services or increase risk of psychological symptoms, making examination of moderators important.

\section{Current Study}

Addressing the gap in CCR programs that focus on victims, the current study assesses the impact of two approaches within a CCR 
program in a single jurisdiction in a large urban city in the Rocky Mountain West of the United States. The overarching goal of the CCR program was to coordinate responses to IPA victims across an interdisciplinary team of law enforcement, prosecution, and community-based service agencies to improve victim psychological distress and safety (see DePrince, Belknap, Labus, Buckingham, \& Gover, in press, for discussion of criminal justice outcomes from this CCR). Within that overarching goal, two approaches were used: community-based outreach (Outreach) and criminal justice system-based referral (Referral).

\section{Commonalities Across Outreach and Referral}

Following the initial report to law enforcement, system-based victim advocates attempted to contact victims to assess victim needs. Details about the IPA incidents, including the information gathered by system-based advocates, were then discussed by an interdisciplinary victim-service team composed of criminal justice system and community-based victim-service professionals.

\section{Unique Aspects of Outreach}

For the Outreach condition, the interdisciplinary victim-service team identified a specific community-based agency to initiate phone outreach to each victim based on her unique case and needs. Outreach by community-based agencies offered women a confidential means of learning about and accessing support and services, while not requiring women to initiate their own search for services in the aftermath of IPA. During the Outreach phone call, community-based advocates told women that they were calling because of the police-reported IPA. The advocates then described the specific services available at that agency (e.g., legal advocacy, counseling, shelter) and provided a nuanced explanation of how those specific services might cater to each victim's particular needs. Further, because the community-based advocate making the outreach call already had basic details about the IPA incident from the interdisciplinary team review, the victim did not have to describe the incident to learn about services. Because the outreach phone conversation was confidential, women could freely disclose information about their reactions or needs related to the IPA.

\section{Unique Aspects of Referral Condition}

For the Referral condition, a system-based advocate from the prosecuting attorney's office or police department contacted women to make referrals to community-based agencies based on recommendations from the interdisciplinary victim-service team. In these calls, system-based advocates offered victims only basic information about agencies, and the conversation was not confidential. The onus was then on women to initiate calls to community-based agencies, at which time women would have to describe their cases (e.g., to an intake worker) to learn more about services.

\section{Predictions}

The Outreach condition was designed to initiate contact with women from community-based victim-service agencies that could provide confidential services specific to each woman's needs. Thus, our primary prediction was that Outreach (compared with
Referral) would be associated with greater decreases in common victim IPA reactions (PTSD, depression, and fear). A secondary prediction was that Outreach (relative to Referral) would lead to better victim safety outcomes, including greater readiness to leave the abusive relationship and decreases in revictimization. To our knowledge, this is the first CCR evaluation focused on victims and the only one using a randomized control, longitudinal design. Participants were interviewed by a separate research team as close to the IPA incident as possible (Time 1 [T1]) and then 6 (T2) and 12 (T3) months later. Psychological distress (i.e., PTSD, depression, and fear) and victim safety (i.e., revictimization, readiness to leave the abusive relationship) outcomes were assessed, while taking into account potential moderators (socioeconomic status, living with the offender, physical or economic dependence on the offender, and ethnic minority status).

\section{Method}

All study procedures and measures were reviewed and approved by a university-based Institutional Review Board.

\section{Participants}

The research team obtained publicly accessible police reports to evaluate inclusion and exclusion criteria. Reports were used for recruitment if the incident involved nonsexual IPA (incident reports for sex crimes are not publicly available and therefore could not be accessed for this project); a female, adult victim; and a male, adult offender. Reports were excluded if women were monolingual non-English speakers and if there was a cross arrest (i.e., if both male and female partners were arrested). Finally, police reports had to provide some form of valid contact information for victims. Based on these criteria, we attempted to contact 827 women; 236 (29\%) were enrolled in the study. Additional details about participant recruitment are described in DePrince et al. (in press). Figure 1 illustrates the participant flow through the study.

\section{Materials}

Symptom measures. PTSD symptom severity was assessed with the Posttraumatic Stress Diagnostic Scale (PDS; Foa, Cashman, Jaycox, \& Perry, 1997), a 49-item measure based on Diagnostic and Statistical Manual of Mental Disorders (4th ed.; DSMIV; American Psychiatric Association, 1994) criteria for PTSD. A total score that reflects PTSD symptom severity was calculated by summing all items. At T1, many women did not meet the time requirement for PTSD; thus, we comment only on symptom severity and not PTSD diagnostic status. Coefficient alphas were as follows for each time point: $\mathrm{T} 1=.82, \mathrm{~T} 2=.93, \mathrm{~T} 3=.93$. Depression symptoms were assessed with the Beck Depression Inventory-II (BDI; Beck, Steer, Ball, Ranieri, 1996), one of the most widely used self-report measures of depression with high validity and reliability. This 21 -item measure assesses depression symptoms based on $D S M-I V$ criteria. The summed items create a total depression score. Coefficient alphas were as follows for each time point: $\mathrm{T} 1=.89, \mathrm{~T} 2=.91, \mathrm{~T} 3=.91$. Fear was assessed using the Fear scale of the Trauma Appraisal Questionnaire (TAQ; DePrince et al., 2010). The TAQ is a 54-item self-report measure of posttraumatic appraisals that has demonstrated reliability and 


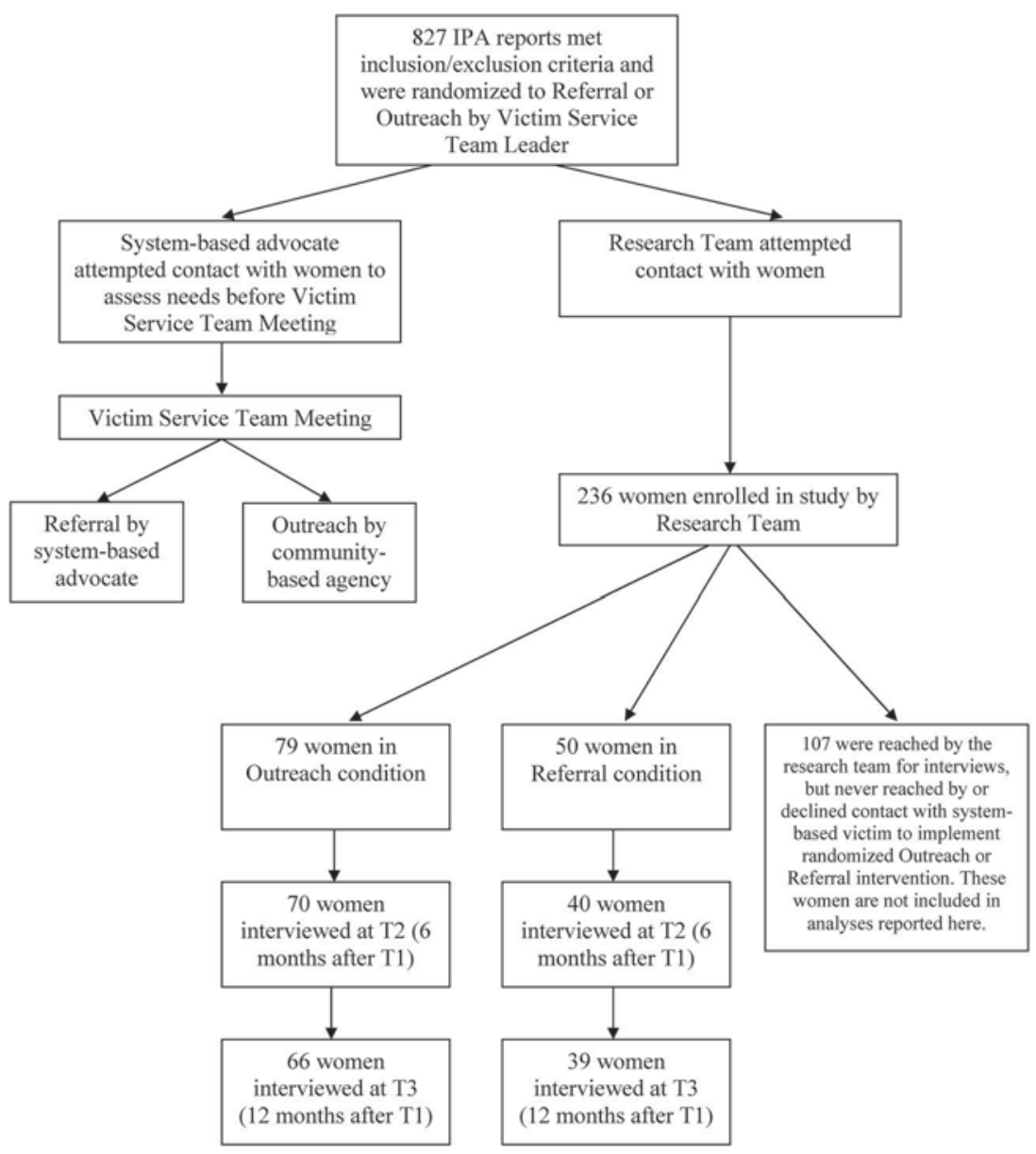

Figure 1. Flow of participants through the study. IPA $=$ intimate partner abuse; $\mathrm{T} 1=$ Time $1 ; \mathrm{T} 2=$ Time 2 ; $\mathrm{T} 3=$ Time 3.

validity. Women were asked to think about current feelings in relation to thinking about target IPA event while answering the TAQ. Coefficient alphas for the TAQ fear scale were as follows: $\mathrm{T} 1=.93, \mathrm{~T} 2=.91, \mathrm{~T} 3=.90$.

Victim safety. The occurrence of new IPA incidents during the study period was assessed using items from the Revised Conflict Tactics Scale (CTS; Straus, Hamby, Boney-McCoy, \& Sugarman, 1996). The CTS is a widely used and well-validated instrument for assessing the use of psychological, physical, and sexual aggression in relationship conflict. Revictimization was present if women reported one or more tactics within each category (psychological, physical, and/or sexual) was used against them at $\mathrm{T} 2$ or T3. Women were asked about aggression perpetrated by the partner from the initial incident as well as new partners.

Women's readiness to leave the relationships with the offender was assessed using an adaptation of the Stages of Change-Short Form (e.g., DiClemente et al., 1991), a widely used measure based on the Stages of Change model (e.g., Prochaska \& DiClemente, 1983). Consistent with Burke, Mahoney, Gielen, McDonnell, and O'Campo (2009), the current study used five questions to determine stage of change: (a) Are you currently in a relationship with [the offender]? (b) If not, have you been out of the relationship for over 6 months? (c) Are you thinking about leaving the relationship sometime in the next 6 months? (d) Are you planning to leave the relationship in the next 30 days? and (e) Have you left the relationship or tried to leave sometime in the past year? Women's responses were coded as follows: still in a relationship with the offender and not considering leaving in the next 6 months coded as 1 (precontemplation), still in the relationship with the offender but considering leaving in the next 6 months (and not planning to leave in the next 30 days) coded as 2 (contemplation), planning to leave in the next 30 days and had previously left or tried to leave the relationship in the past year were coded as 3 (preparation), left the relationship within the past 6 months coded as 4 (action), left the relationship over 6 months ago coded as 5 (maintenance).

Service utilization and therapy. At each time point, we asked participants about their experiences with services from community-based agencies on the CCR team as well as talking to a therapist. We calculated the percentage of women who reported contact with these agencies at some point during the study period. In addition, at Time 2 and Time 3, we developed a question to ask women to rate the helpfulness of contacts with community-based agencies as well as the police department victim assistance unit over the previous 6 months (i.e., from T1 to T2, measured at T2; 
and from T2 to T3, measured at T3). For each agency, women responded on a scale of 1 to $5(1=$ they made things much harder, $3=$ they didn't really make things easier or harder, and $5=$ make things a lot easier). The same question about helpfulness was asked for therapy services. Because we did not have predictions about time per se, we averaged women's T2 and T3 responses across agencies to derive a single score for victim service and therapy helpfulness.

Moderators. Participant characteristics may influence intervention outcomes (Kraemer, Frank, \& Kupfer, 2006). Therefore, exploratory hypothesis generating moderator analyses have been highly recommended because the results of these analyses can have important implications for clinical work, research, and policy development. We examined the moderating effects of socioeconomic status, perceptions of dependence on the offender, and ethnicity. Socioeconomic status was assessed with three variables: highest level of education, occupation, and income. Living with the offender was assessed by asking women whether they lived with the offender at the time of the incident that led to the police report (yes/no). Perceptions of physical and economic dependence on the offender were assessed with two questions: (a) "How dependent on [partner's name] were you for your physical wellbeing?" $(1=$ not at all dependent to $5=$ entirely dependent $)$ and (b) "How important to your financial stability was the money [partner's name] brings home?" $(1=$ not at all important to $5=$ absolutely necessary). Ethnicity was a dichotomous variable coded as -1 for women who identified only as White and 1 for women who identified with any racial or ethnic minority group.

\section{CCR Intervention Procedure}

Prior to daily interdisciplinary team meetings, the team leader applied an algorithm to randomly assign all victims identified in police reports to Outreach or Referral conditions. Also prior to the team meetings, a system-based advocate attempted initial contact with victims to assess their needs. Importantly, victims did not receive the Outreach or Referral interventions if they (a) could not be reached within 3 business days by the system-based advocate (as this meant the system-based advocate could not assess their needs to share with the interdisciplinary team) or (b) told the system-based advocate that they wanted no further contact.

At the interdisciplinary team meeting, the team conducted empirically guided risk assessments on a case-by-case basis to identify women who appeared to be at grave risk for imminent serious harm or fatality. Victims who the team determined to be at grave safety risk were not eligible for the study and were automatically referred for community-based outreach. The interdisciplinary team was blind to the Outreach/Referral condition assignment until after the risk assessment to assure that risk was not evaluated differently depending on condition assignment.

Once the risk assessment was completed, the condition assignment was revealed to the interdisciplinary team. Among women randomly assigned to the Outreach condition, the interdisciplinary team chose the most appropriate lead community-based agency to address each victim's needs. Victim advocates from the lead community-based agency were then responsible for making phone outreach to victims to offer services. For those assigned to the Referral condition, a system-based victim advocate called women to make referrals to community-based agencies; women in the
Referral condition could then contact community-based agencies themselves if they so desired.

\section{Research Procedure}

The research team retrieved publicly accessible police incident reports from the Denver, Colorado Police Department several times per week. Within a day of retrieving these incident reports, the research team sent lead letters inviting women to participate in a Women's Health Study. Approximately 3 days after the lead letter was mailed, research staff initiated phone calls to invite potential participants. Recruiting materials (lead letters, phone scripts) did not mention IPA to decrease safety risks to potential participants. During the initial phone contact, potential participants were invited to attend a 3-hr interview. Women who indicated that they would have to take public transportation to the interview were offered cab rides.

Participants were greeted by a female interviewer (a graduatelevel interviewer and/or the principal investigator) who was blind to the intervention condition. During the consent process, women were told that their names had been identified from police reports. Participants were informed about the scope of the study as well as their rights as participants. Participants completed a "consent quiz" designed to assess understanding of the consent information. Following consent procedures, participants completed the interview and questionnaires. At the end of the session, participants were asked to complete questions to monitor responses to study procedures.

Approximately 3 weeks prior to follow-up interview due dates, a lead letter was sent letting women know that the researchers would be calling to schedule a follow-up interview. Approximately 2 weeks prior to T2 and T3 interview dates, we began calling women to schedule the T2/T3 interview. When women arrived for the follow-up interviews, we reviewed consent information and readministered the consent quiz. Participants then completed the interview and questionnaires after the consent review procedures. At the end of each interview, women were compensated for their time ( $\$ 50$ at T1, $\$ 55$ at T2, and $\$ 60$ for T3) and debriefed. At the end of each interview, women were offered a newsletter that provided referrals to community agencies dealing with health and violence issues.

\section{Analysis Plan}

Primary outcome variables. Intent to treat contrast analyses were performed to test for hypothesized intervention-induced decreases in the primary outcome variables (PSTD, depression, fear) using a general linear mixed model in SAS (Version 9.2). Participants were specified as a random effect, as this designation produced the best fitting error-covariance structure based on model fit indices (Akaike information criterion, Bayesian information criterion). We modeled the primary outcomes using second degree polynomial functions of time (i.e., linear, quadratic effects) and their interaction with condition (Outreach or Referral). Specific a priori contrasts of interests included differences in symptom change on the primary outcomes between Outreach and Referral conditions from $\mathrm{T} 1$ to $\mathrm{T} 2, \mathrm{~T} 2$ to $\mathrm{T} 3$, and $\mathrm{T} 1$ to $\mathrm{T} 3$. In addition, effect sizes were calculated using Cohen's $d$. For each primary outcome analyses, we graph response trajectory over time by 
group, presenting parameter estimates and $95 \%$ normal confidence intervals. To control for measurement variability of the instruments used to measure PTSD, fear, and depression, we used a completers-only approach to calculate each participant's reliable change index (RCI) from T1 to T3 using reliability and standard deviation estimates from independent samples (Evans, Margison, \& Barkham, 1998). Fisher's exact test was then applied to test for group differences in RCI.

Moderator analyses. To test whether trajectories for outcomes differed between Outreach and Referral groups depending on the level of the hypothesized moderator variables, we used a general linear mixed model (GLMM) with sequential sum of squares (for further details on the method, see Holroyd, Labus, \& Carlson, 2009). Moderator effects are described in Table 1 by displaying parameter estimates and $95 \%$ normal confidence intervals at clinically meaningful levels of the moderator variables. Given the inherent problems in conducting a moderator analysis in a moderate size trial $(N<400$ participants; Holroyd et al., 2009; Kraemer, Wilson, Fairburn, \& Agras, 2002), we do not provide $p$ values. As an alternative, we calculate effect sizes (Cohen's $d$; J. Cohen, 1992) to elucidate the nature of moderator effects. By convention $d=0.20, d=0.50$, and $d=0.80$ are interpreted as small, moderate, and large effect sizes, respectively. We consider these moderator analyses descriptive and hypothesis-generating rather than hypothesis-testing. In the interests of space, we do not report on nonsignificant moderator analyses.

Secondary outcome variables. GLMMs were also applied to examine the effects of condition on secondary outcome variables: service usage, revictimization, and stage of change.

\section{Results}

\section{Participant Demographics}

Participants $(M$ age $=33.8$ years, $S D=11.1)$ described their ethnic backgrounds as 33\% White/Caucasian, 29\% Black or Af- rican American, 2\% Asian/Asian American or Pacific Islander, 14\% American Indian or Alaskan Native, and 42\% Hispanic/ Latina. Across ethnic group categories, $76 \%$ of women identified with at least one ethnic minority group. To capture socioeconomic status in a single global score, a principal component analysis using orthogonal rotation was applied to education, occupation, and income variables in the full sample. A single component solution emerged (all component loadings above .75); each individual's factor score was used in analyses. Median yearly net income was $\$ 7,644$, with a range of $\$ 0$ to $\$ 108,000$. Fifty-one percent of women indicated that they lived with the offender at the time of the incident. Twenty-two percent of women reported some degree of physical dependence on the offender, whereas $50 \%$ of women reported some degree of economic dependence. For additional details about demographics, see DePrince et al. (in press).

We used spatial data to explore the representativeness of the sample. Using geo-coded addresses, we compared where participants reported living at the time of the incident with the addresses of all IPA incidents reported across the county during the recruitment period (see DePrince et al., in press, for additional details about this comparison). As illustrated in Figure 2, participants reported addresses that appear to represent the spatial locations of IPA incident reports and, therefore, spatially relevant demographic variables (e.g., ethnicity, income).

\section{Primary Outcome Variables: Effects of Condition (Outreach, Referral) and Moderators}

As detailed in DePrince et al. (in press), Outreach and Referral conditions were equivalent on demographic variables (e.g., ethnic minority status, age, education, occupation, and income) as well as IPA-relevant variables (e.g., description of relationship to offender, experiences of IPA in the 6 months prior to the target incident). Figure 3 provides estimated means and standard errors for primary outcomes.

Table 1

Within- and Between-Group Effect Sizes and 95\% Confidence Intervals Stratified by Moderators

\begin{tabular}{|c|c|c|c|c|}
\hline Variable & Intervention group & $\mathrm{T} 1-\mathrm{T} 3$ & $\mathrm{~T} 1-\mathrm{T} 2$ & $\mathrm{~T} 2-\mathrm{T} 3$ \\
\hline & \multicolumn{4}{|c|}{ Perceptions of physical dependence on offender moderates group effects on fear } \\
\hline \multirow[t]{3}{*}{ Total physical dependence } & Outreach & $-0.23(-.54, .08)$ & $-.28(-.59, .03)$ & $0.07(-0.24,0.38)$ \\
\hline & Referral & $0.01(-.38, .40)$ & $.03(-.36, .42)$ & $-0.01(-0.40,0.37)$ \\
\hline & Outreach minus Referral & $-0.29(-.64, .06)$ & $-.32(-.68, .03)$ & $0.08(-0.27,0.44)$ \\
\hline \multirow[t]{3}{*}{ Partial physical dependence } & Outreach & $-0.10(-0.41,0.21)$ & $-0.18(-0.49,0.13)$ & $0.10(-0.21,0.41)$ \\
\hline & Referral & $0.09(-0.30,0.48)$ & $0.13(-0.26,0.52)$ & $-0.07(-0.46,0.32)$ \\
\hline & Outreach minus Referral & $-0.01(-0.36,0.34)$ & $-0.20(-0.55,0.16)$ & $0.15(-0.20,0.50)$ \\
\hline \multirow[t]{3}{*}{ No physical dependence } & Outreach & $0.75(0.43,1.07)$ & $0.59(0.28,0.91)$ & $0.12(-0.19,0.43)$ \\
\hline & Referral & $0.40(0.01,0.80)$ & $0.56(0.16,0.95)$ & $-0.16(-0.54,0.23)$ \\
\hline & Outreach minus Referral & $0.33(-0.03,0.68)$ & $0(-0.35,0.35)$ & $0.34(-0.01,0.70)$ \\
\hline \multicolumn{5}{|c|}{ Ethnicity moderates group effects on fear } \\
\hline \multirow[t]{3}{*}{ Ethnic minority } & Outreach & $0.74(0.42,1.06)$ & $0.62(0.30,0.94)$ & $0.12(-0.19,0.43)$ \\
\hline & Referral & $0.40(0.01,0.79)$ & $0.47(0.07,0.86)$ & $-0.05(-0.44,0.34)$ \\
\hline & Outreach minus Referral & $0.31(-0.05,0.66)$ & $0.12(-0.23,0.48)$ & $0.18(-0.17,0.53)$ \\
\hline \multirow[t]{3}{*}{ Not ethnic minority } & Outreach & $0.25(-0.06,0.56)$ & $0.08(-0.23,0.39)$ & $0.17(-0.14,0.48)$ \\
\hline & Referral & $0.20(-0.19,0.59)$ & $0.52(0.13,0.92)$ & $-0.31(-0.70,0.08)$ \\
\hline & Outreach minus Referral & $0.07(-0.28,0.42)$ & $-0.01(-0.36,0.34)$ & $0.47(0.12,0.83)$ \\
\hline
\end{tabular}

Note. The parameters represent effect size of change, with $95 \%$ confidence intervals in parentheses. Effect size was calculated using the parameter estimates and standard error from the general linear mixed model. 


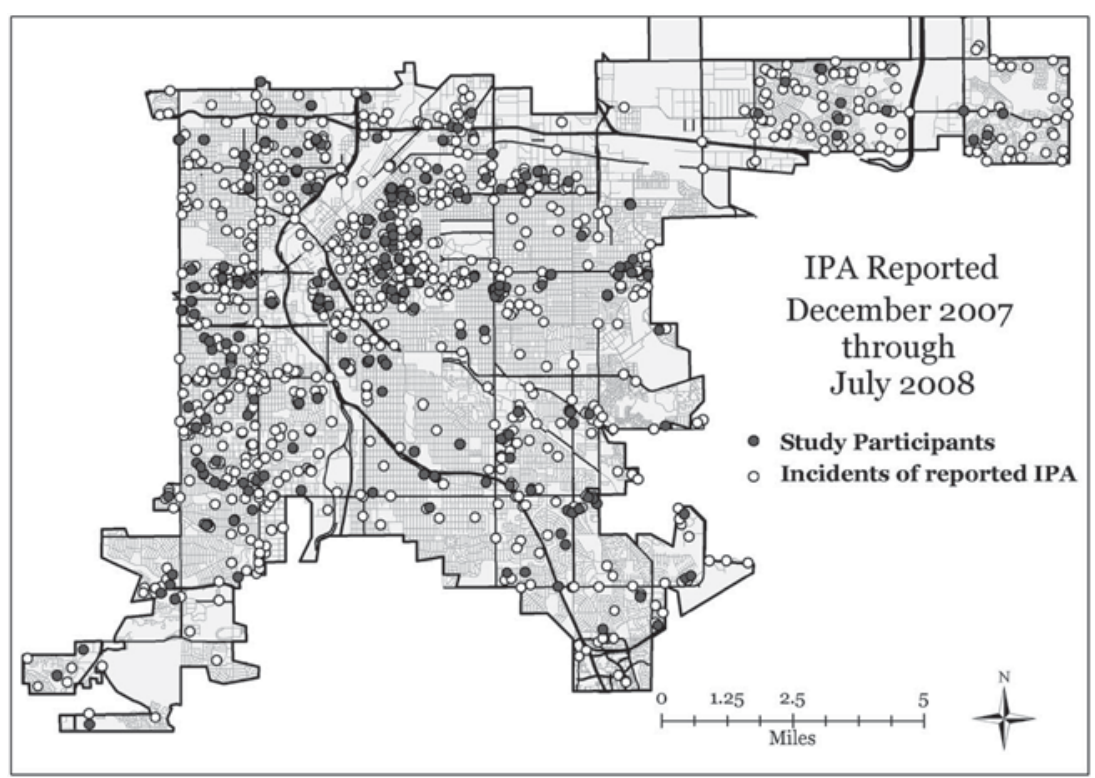

Figure 2. Participants' addresses relative to location of overall intimate partner abuse (IPA) reports during the recruitment period. Copyright 2011 by Susan Buckingham. Reprinted with permission.

PTSD total symptoms. PTSD symptom severity scores decreased significantly $\mathrm{T} 1$ to $\mathrm{T} 2$ for Outreach, $t(206)=3.33, p=$ .001 , Cohen's $d=0.34(0.03,0.66)$, and Referral, $t(211)=4.48$, $p<.0001, d=0.60(0.20,1.00)$, conditions (see Figure $3 \mathrm{~A})$. Differences in symptom change from $\mathrm{T} 1$ to $\mathrm{T} 2$ in Referral relative to Outreach conditions did not achieve statistical significance, $t(207)=-1.59, p=.11, d=-0.29(-0.68,0.11)$. From T2 to T3, reduction in symptom severity was maintained among women in the Outreach condition, $d=0.08(-0.02,0.39)$, but symptom severity increased for the Referral condition, $t(204)=-2.11, p=$ $.04, d=-0.28(-.0 .67,0.11)$. As such, we observed significant differences between Outreach and Referral conditions in symptom change T2 to T3, $t(203)=2.18, p=.03, d=0.40(0.04,0.75)$. For both interventions, within-group effect size change from T1 to T3 in PTSD symptom severity was moderate: Outreach condition $d=$ $0.43(0.11,0.74)$, and Referral condition $d=0.31(-0.08,0.70)$. RCI of 8.77 was calculated based on a reliability sample, where Cronbach's alpha for PTSD $=0.93(S D=11.96$; DePrince et al., 2011). For the Outreach condition, 22 (34\%) of 64 individuals demonstrated reliable change at Time 3 . For the Referral condition, only $11(29 \%)$ of 38 individuals showed reliable change. Fisher's exact test indicated no significant differences between groups on RCI for PTSD ( $\left.\chi^{2}=2.32, p=.14\right)$. Relative risk computations indicated that reliable change is twice as likely for Outreach compared with Referral.

Depression symptoms. Depressive symptoms significantly decreased from $\mathrm{T} 1$ to $\mathrm{T} 2$ in the Outreach, $t(204)=2.16, p=$ $.0319, d=0.22(-0.09,0.53)$, and Referral, $t(212)=3.84, p=$ $.0002, d=0.52(-0.12,0.91)$, conditions. As illustrated in Figure $3 \mathrm{~B}$, symptom change from $\mathrm{T} 1$ to $\mathrm{T} 2$ showed a trend to be greater in the Referral condition compared with the Outreach condition, $t(209)=-1.81, p=.07, d=-0.33(-0.069,0.02)$. From T2 to T3, women in the Outreach condition showed a trend for continued improvement, $t(199)=1.51, p=.13, d=0.15(-0.16,0.46)$, whereas women in the Referral condition appeared to worsen, $t(365)=-1.54, p=.12, d=-0.21(-0.60,0.18)$. Because of relapse of depressive symptoms in the Referral condition, comparison of symptom change T2 to T3 was significantly different, $t(202)=2.13, p=.03, d=0.39(0.04,0.75)$. Overall, from $\mathrm{T} 1$ to T3, both Outreach, $t(206)=3.61, p=.0004, d=0.37(0.06$, $0.69)$, and Referral, $t(210)=2.26, p=.02, d=0.30(-0.09,0.69)$, conditions showed moderate decreases in depressive symptoms. RCI of 8.50 was calculated based on a reliability sample where Cronbach's alpha for depression $=0.90(S D=9.76$; DePrince et al., 2011). For the Outreach condition, 17 (28\%) of 61 individuals demonstrated reliable change at Time 3, whereas for the Referral condition, 5(14\%) of 35 individuals showed reliable change. Fisher's exact test indicated no significant differences between the groups on RCI for depression $\left(\chi^{2}=2.32, p=.14\right)$.

Fear. Similar decreases from $\mathrm{T} 1$ to $\mathrm{T} 2$ in fear symptoms, $t(206)=.55, p=.58$, were observed for both the Outreach, $t(205)=5.26, p<.0001, d=0.59(0.28,0.91)$, and Referral, $t(206)=4.69, p<.0001, d=0.67(0.27,1.07)$, conditions (see Figure 3C). From T2 to T3, there was a trend for continued reduction in symptoms for the Outreach condition, $t(199)=1.68$, $p=.09, d=0.18(-0.13,0.49)$, concurrent with a trend for relapse of fear symptoms in the Referral condition, $t(201)=-1.48, p=$ $.14, d=-0.21(-0.61,0.18)$, resulting in significant differences between Outreach and Referral for fear symptom change T2 to T3, $t(200)=2.19, p=.03, d=0.40(0.05,0.76)$. Because of the reinstatement of fear symptoms for the Referral condition from T2 to T3, there was a trend from T1 to T3, $t(207)=1.70, p=.09, d=$ $-0.31(-0.024,0.66)$, for the Outreach condition, $t(205)=6.92$, $p<.0001, d=0.77(0.45,1.09)$, to report greater reductions in fear symptoms than the Referral condition, $t(208)=3.18, p=$ $.0017, d=0.45(0.06,0.85)$. RCI of .89 was calculated based on a reliability sample, where Cronbach's alpha for fear $=0.89$ ( $S D=0.97$; DePrince et al., 2011). For the Outreach condition, 31 

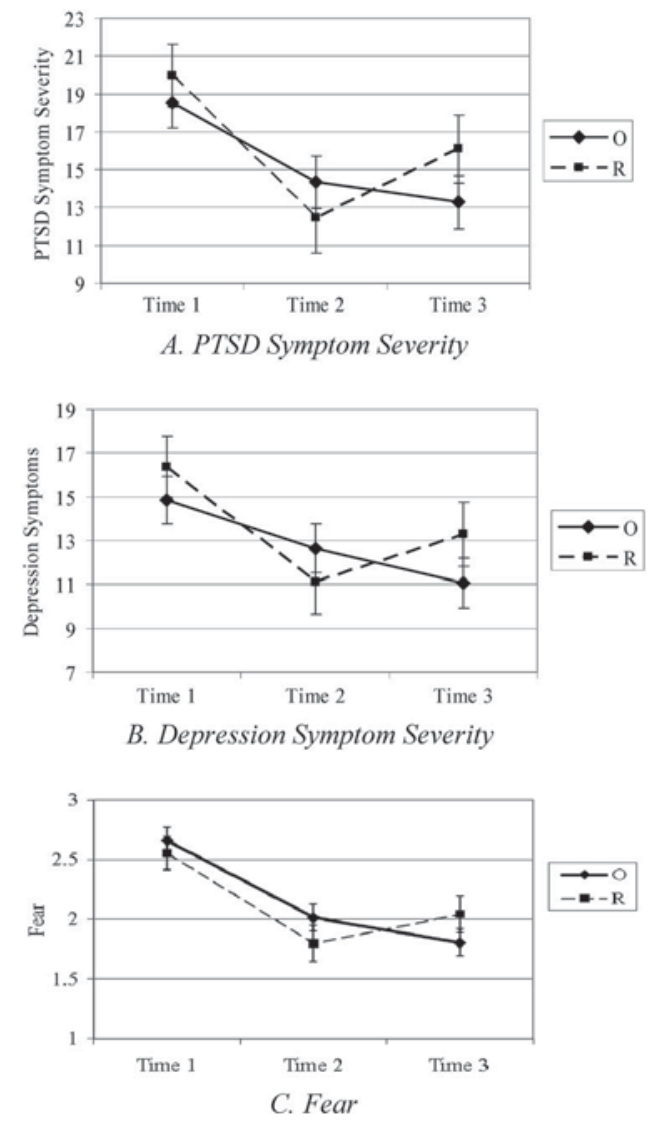

Figure 3. Estimated means (with standard error bars) for primary outcome variables by time and condition. PTSD $=$ posttraumatic stress disorder; $\mathrm{O}=$ community-based outreach; $\mathrm{R}=$ criminal justice systembased referral.

$(51 \%)$ of 61 individuals demonstrated reliable change at Time 3 , whereas for the Referral condition, only 10 (28\%) of 36 individuals showed reliable change. Fisher's exact test indicated significant differences between the groups on RCI for fear $\left(\chi^{2}=4.93\right.$, $p=.03)$. Relative risk computations indicated that reliable change is twice as likely for Outreach compared with Referral.

Ethnicity significantly moderated the quadratic, $F(1,199)=$ $5.81, p=.02$, and main effects, $F(1,119)=3.46, p=.07$, of condition on TAQ fear scores (see Figure 4). For individuals identifying as ethnic minorities, both interventions yielded moderate to large reductions in symptoms-Outreach T1-T3 $d=$ $0.074(0.42,1.06), \mathrm{T} 1-\mathrm{T} 2 d=0.62(0.30,0.94)$; Referral T1-T3 $d=0.40$ (0.01, 0.79), T1-T2 $d=0.47(0.07,0.86)$ —with trends suggesting Outreach had a greater effect than Referral: Outreach Referral, T1-T3 $d=0.31(-0.05,0.66)$. For ethnic majority participants, only the Referral condition showed significant decrease in PTSD symptoms T1-T2, $d=0.53(0.13,0.92)$; however, an apparent relapse in symptoms in these individuals, $d=-0.31$ $(-0.70,0.08)$, resulted in small overall effects for Referral, $d=$ $0.20(-0.19,0.59)$, compared with Outreach, $d=0.25(-0.06$, $0.56)$.

Women's perceptions of physical dependence on the offender moderated the linear, $F(1,166)=4.43, p=.04$, effects of
Condition on TAQ fear scores. For individuals who report not being at all dependent on the offender, both Outreach, $d=0.75$ $(0.43,1.07)$, and Referral, $d=0.40(0.01,0.80)$, conditions led to moderate-to-large reductions in fear over time; a trend suggested the greatest reduction for the Outreach condition: Outreach Referral, T1-T3 $d=0.33(-0.03,0.68)$. However, for individuals who reported partial or total dependence on the offender, neither Outreach nor Referral conditions had significant effects on fear.

\section{Secondary Outcome Variables}

Victim safety. In terms of continued aggression by target offenders, $75 \%$ and $81 \%$ of women in the Outreach and Referral conditions, respectively, reported at least one incident that involved psychological aggression; $30 \%$ and $29 \%$, respectively, reported physical aggression; and $32 \%$ and $26 \%$, respectively, reported sexual aggression. In terms of aggression by new offenders, $24 \%$ of women in the Outreach condition and $24 \%$ of women in the Referral condition reported psychological aggression; $15 \%$ and $10 \%$ reported physical aggression, respectively; and $8 \%$ and $7 \%$ reported sexual aggression, respectively. Chi-square test of links between the presence/absence of revictimization by Outreach/ Referral conditions for the target offender and new partners were nonsignificant.

To characterize women's plans for staying/leaving relationships with the offender from the target incident, we examined Stages of Change scores at T3. Compared with women in the Referral condition $(M=3.43, S D=1.86)$, women assigned to the Outreach condition $(M=4.15, S D=1.26)$ had higher Stages of Change scores at T3, equal variances not assumed, $t(56.60)=2.07, p=$ .04. Higher scores indicate greater likelihood of having left the relationship or having a plan to do, with a medium effect size, Cohen's $d=0.47(0.06,0.89)$.
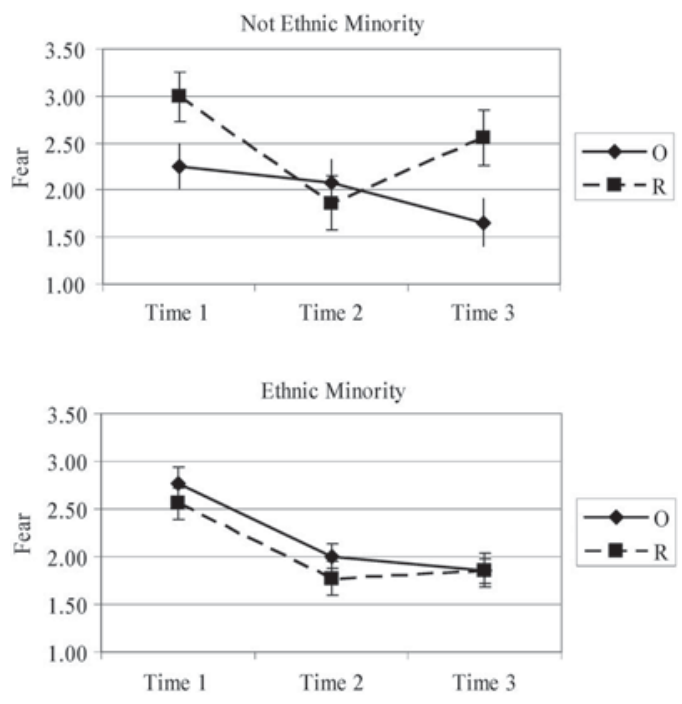

Moderating effect of ethnicity on fear over time

Figure 4. Estimated means (with standard error bars) for moderator analyses for fear by time and condition. $\mathrm{O}=$ community-based outreach; $\mathrm{R}=$ criminal justice system-based referral. 
Service utilization. We examined contact with any of the community-based agencies on the interdisciplinary team over time but found no differences between the Outreach and Referral conditions using chi-square analyses. At T1, $48 \%$ of women in the Outreach condition and $38 \%$ of women in the Referral condition reported contact with at least one community-based agency. Contact with community agencies at T2 was made by $32 \%$ and $37 \%$ of women in the Outreach and Referral conditions, respectively; and at T3 contact was made by $19 \%$ and $13 \%$ of women in the Outreach and Referral conditions, respectively. Likewise, groups did not differ in the likelihood that they spoke with a therapist over the follow-up period: At T2, $41 \%$ and $33 \%$ women in the Outreach and Referral conditions, respectively, reported contact with a therapist; those rates were $30 \%$ and $37 \%$, respectively, at T3. The groups did differ, however, in how helpful they found their contacts with system- and community-based CCR team members, $t(76)=2.28, p=.03$. According to average ratings of helpfulness of contacts with community-based agencies and the Denver Police Department Victim Assistance Unit at T2 and T3, women in the Outreach condition reported greater perceptions of the helpfulness of contacts $(n=47 ; M=3.67, S D=0.79)$ than women in the Referral condition $(n=31 ; M=3.21, S D=0.98)$. The effect size was medium, Cohen's $d=0.53(0.07,0.98)$. In contrast, groups did not differ in how helpful they rated contacts with therapists across the follow-up period (Outreach $n=30, M=3.98, S D=$ 0.89; Referral $n=18, M=3.92, S D=1.15$ ).

\section{Discussion}

Using a randomized control, longitudinal design, this research demonstrates that community-based Outreach from victim advocates for women exposed to police-reported IPA results in decreases in distress 1 year later. Women in the community-based Outreach condition reported greater decreases in both PTSD and depressive symptom severity and fear 1 year later, compared with women in the Referral condition. In contrast, women in the Referral condition reported increases in symptoms from T2 to T3, suggesting that community outreach by system victim advocates may have important prevention influences long after the abuse occurs. These findings point to the importance of future research on the role that community-based victim advocates can play in addressing distress following IPA in addition to other more frequently studied responders, such as therapists and medical providers.

Moderator analyses revealed that community-based outreach was almost three times more effective for ethnic minority women in decreasing fear, compared with White women. Although moderate to large decreases in fear were observed among ethnic minority women, only small decreases were observed among White women. This finding may have particularly important implications for the intersection of psychological well-being and criminal justice participation. Fear is important not only to psychological outcomes (DePrince et al., 2010) but also criminal justice participation (Belknap \& Sullivan, 2003; Fischer \& Rose, 1995; Goodman, Bennett, \& Dutton, 1999). Given the overrepresentation of ethnic minority women in the criminal justice system as victims (Gabbidon \& Green, 2008), outreach may be valuable for decreasing victim fear and increasing women's engagement in the criminal justice system.
Community-based outreach was less effective for women who perceived greater physical dependence on the offender, relative to their peers; however, economic dependence on the offender did not moderate the impact of outreach. The absence of an effect for economic dependence is interesting because survivors who are economically dependent on their abusers have been found to be less likely to engage the criminal legal system in the future (e.g., Erez \& Belknap, 1998; Fleury-Steiner, Bybee, Sullivan, Belknap, $\&$ Melton, 2006). Further, economic disadvantage has been found to increase women's risk of violence among intimate partners (Benson \& Fox, 2004). However, we did not see evidence of the impact of economic dependence on psychological distress here. Instead, we found that physical dependence moderated the impact of the intervention. To our knowledge, physical dependence on the offender has not received attention in the empirical literature. Thus, future work should identify the mechanisms by which physical dependence on the offender exerts an influence on women's well-being and interventions that can effectively support these women.

Women faced significant ongoing danger following policereported IPA. Even though this sample was recruited from incident reports indicating nonsexual IPA, nearly one third of women in the sample reported that the target offender engaged in at least one sexually aggressive tactic in the year following the T1 interview. For almost one third of the women, conflicts with the offender continued to be physically aggressive. Roughly one quarter of women reported that a new partner engaged in at least one psychologically aggressive tactic. In addition, $7-15 \%$ of women reported physically aggressive or sexually aggressive behaviors by new partners. Thus, women continued to face significant safety risks over the follow-up year.

We originally predicted that outreach would increase victim safety by preventing revictimization by the abuser; however, we came to think differently about this prediction with hindsight. Although other research suggests that contacts with advocates and/or outreach are associated with positive effects in terms of victim engagement with the criminal legal system (DePrince et al., in press) and improved victim well-being (reported here), these things are, to some degree, within women's capacity to influence. For example, women can exert control over decisions to engage with the legal system and to seek services and/or other support that may mitigate symptoms. Women, however, cannot control their partners' behaviors. Thus, predicting that outreach to victims would increase safety failed to take into account specific domains in which women may or may not be able to effect change in their lives. Although outreach did not affect victim safety, women assigned to the Outreach (relative to Referral) condition had higher stage of change scores, indicating they were more likely to articulate plans to leave or to have already left the offender at T3. This suggests that outreach is associated with changes that are more directly in women's control (e.g., plans to leave) than in offenders' control (e.g., whether he engages in aggressive behaviors).

Across the two conditions, women did not differ in terms of contact with community-based agencies or therapists during the study period. Community-based Outreach did not improve on women's overall access to victim advocacy or therapy services; however, the groups did differ in their perceptions of how helpful advocacy services were (but not therapy). In particular, women assigned to the Outreach condition reported that their victim- 
service contacts were more helpful than did women in the Referral condition. Community-based outreach was implemented by an agency selected based on each victim's needs; thus, women may have connected more quickly or more successfully with relevant services, which helped their coping and well-being overall (as reflected in reduced symptoms of distress, for example). Women in the Referral condition may have failed to find the fit required to address their specific needs as they worked their way through the complex world of victim services.

\section{Study Limitations}

We did not have data on women's contact with system- or community-based personnel prior to T1; therefore, we do not know what (if any) effect the initial contact with system-based advocates had on women prior to T1. We had no feasible way of interviewing women prior to their first contact with system-based advocates (e.g., police department advocates sometimes go to the scene of incidents). However, because both groups were contacted by a system-based advocate, this initial contact was held constant across groups. We had no way of testing the randomization to groups or controlling for preexisting conditions; however, groups were equivalent on key variables, including reports of exposure to violence in the 6 months prior to the target incident (DePrince et al., in press).

\section{Conclusions}

The current study provides evidence of positive effects of early, coordinated, victim-focused outreach on women's well-being: Community-based outreach from victim advocates through a CCR was linked to decreases in IPA-related mental health problems, including PTSD and depression symptom severity as well as fear. Strikingly, community-based outreach by victim advocates was almost three times more effective for ethnic minority women in decreasing fear compared with White women, whereas physical dependence on the offender mitigated the impact of outreach. Although outreach was linked to greater readiness to leave the offender, women in both conditions reported that ongoing aggression by the original offender was all too common. The findings from this study address historical gaps between victim advocates and mental health providers, demonstrating that research and policy attention should be paid to understanding the role that community-based outreach and interdisciplinary CCRs can play in addressing IPA.

\section{References}

Allen, N. E., Bybee, D. I., \& Sullivan, C. M. (2004). Battered women's multitude of needs: Evidence supporting the need for comprehensive advocacy. Violence Against Women, 10, 1015-1035. doi:10.1177/ 1077801204267658

American Psychiatric Association. (1994). Diagnostic and statistical manual of mental disorders (4th ed.). Washington, DC: Author.

Beck, A. T., Steer, R. A., Ball, R., \& Ranieri, W. (1996). Comparison of Beck Depression Inventories-IA and -II in psychiatric outpatients. Journal Personality Assessment, 67, 588-597. doi:10.1207/ s15327752jpa6703_13

Belknap, J., \& Sullivan, C. M. (2003). Longitudinal study of battered women in the system: The victims' and decision-makers' perceptions:
Final report (Document No. 202946). Washington, DC: National Institute of Justice. Retrieved from http://www.ncjrs.gov/pdffiles1/nij/grants/ 202946.pdf

Benson, M. L., \& Fox, G. L. (2004). Concentrated disadvantage, economic distress, and violence against women in intimate relationships. In B. S. Fisher (Ed.), Violence against women and family violence: Developments in research, practice, and policy (NIJ100709). Washington, DC: National Criminal Justice Resource Center.

Burke, J. G., Mahoney, P., Gielen, A., McDonnell, K. A., \& O'Campo, P. (2009). Defining appropriate stages of change for intimate partner violence survivors. Violence and Victims, 24, 36-51. doi:10.1891/08866708.24.1.36

Bybee, D. I., \& Sullivan, C. M. (2002). The process through which an advocacy intervention resulted in positive change for battered women over time. American Journal of Community Psychology, 30, 103-132. doi:10.1023/A:1014376202459

Bybee, D. I., \& Sullivan, C. M. (2005). Predicting re-victimization of battered women three years after exiting a shelter program. American Journal of Community Psychology, 36, 85-96. doi:10.1007/s10464-0056234-5

Campbell, R., Greeson, M. R., Bybee, D., \& Raja, S. (2008). The cooccurrence of childhood sexual abuse, adult sexual assault, intimate partner violence, and sexual harassment: A mediational model of posttraumatic stress disorder and physical health outcomes. Journal of Consulting and Clinical Psychology, 76, 194-207. doi:10.1037/0022006X.76.2.194

Cattaneo, L. B., \& DeLoveh, H. L. M. (2008). The role of socioeconomic status in helpseeking from hotlines, shelters, and police among a national sample of women experiencing intimate partner violence. American Journal of Orthopsychiatry, 78, 413-422. doi:10.1037/a0014558

Cattaneo, L. B., \& Goodman, L. A. (2005). Risk factors for reabuse in intimate partner violence: A cross-disciplinary critical review. Trauma, Violence, \& Abuse, 6, 141-175. doi:10.1177/1524838005275088

Cattaneo, L. B., \& Goodman, L. A. (2010). Through the lens of therapeutic jurisprudence the relationship between empowerment in the court system and well-being for intimate partner violence victims. Journal of Interpersonal Violence, 25, 481-502. doi:10.1177/0886260509334282

Classen, C. C., Palesh, O. G., \& Aggarwal, R. (2005). Sexual revictimization: A review of the empirical literature. Trauma, Violence, \& Abuse, 6, 103-129. doi:10.1177/1524838005275087

Cohen, J. (1992). A power primer. Psychological Bulletin, 112, 155-159. doi:10.1037/0033-2909.112.1.155

Coker, A. L., Smith, P. H., Thompson, M. P., McKeown, R. E., Bethea, L., \& Davis, K. E. (2002). Social support protects against the negative effects of partner violence on mental health. Journal of Women's Health \& Gender-Based Medicine, 11, 465-476. doi:10.1089/ 15246090260137644

DePrince, A. P. (2005). Social cognition and revictimization risk. Journal of Trauma and Dissociation, 6, 125-141. doi:10.1300/J229v06n01_08

DePrince, A. P., Belknap, J., Labus, J., Buckingham, S. E., \& Gover, A. R. (in press). The impact of victim-focused outreach on criminal legal system outcomes following police-reported intimate partner abuse. $\mathrm{Vi}$ olence Against Women.

DePrince, A. P., Chu, A. T., \& Pineda, A. S. (2011). Links between specific posttrauma appraisals and three forms of trauma-related distress. Psychological Trauma: Theory, Research, Practice, and Policy. Advance online publication. doi:10.1037/a0021576

DePrince, A. P., Zurbriggen, E. L., Chu, A. T., \& Smart, L. (2010). Development of the Trauma Appraisal Questionnaire. Journal of Aggression, Maltreatment \& Trauma, 19, 275-299. doi:10.1080/ 10926771003705072

DiClemente, C. C., Prochaska, J. O., Fairhurst, S., Velicer, W. F., Rossi, J. S., \& Velasquez, M. (1991). The process of smoking cessation: An analysis of precontemplation, contemplation and contemplation/action. 
Journal of Consulting and Clinical Psychology, 59, 295-304. doi: 10.1037/0022-006X.59.2.295

Erez, E., \& Belknap, J. (1998). In their own words: Battered women's assessment of the criminal processing system's responses. Violence and Victims, 13, 251-268.

Evans, C., Margison, F., \& Barkham, M. (1998). The contribution of reliable and clinically significant change methods to evidence-based mental health, Evidence-Based Mental Health, 1, 70-72. doi:10.1136/ ebmh.1.3.70

Fanslow, J. L., \& Robinson, E. M. (2010). Help-seeking behaviors and reasons for help seeking reported by a representative sample of women victims of intimate partner violence in New Zealand. Journal of Interpersonal Violence, 25, 929-951. doi:10.1177/0886260509336963

Fischer, K., \& Rose, M. (1995). When "enough is enough": Battered women's decision-making around court orders of protection. Crime \& Delinquency, 41, 414-429. doi:10.1177/0011128795041004003

Fleury-Steiner, R., Bybee, D. I., Sullivan, C. M., Belknap, J., \& Melton, H. C. (2006). Contextual factors impacting battered women's intentions to re-use the criminal legal system. Journal of Community Psychology, 34, 327-342. doi:10.1002/jcop.20102

Foa, E. B., Cashman, L., Jaycox, L., \& Perry, K. (1997). The validation of a self-report measure of posttraumatic stress disorder: The posttraumatic diagnostic scale. Psychological Assessment, 9, 445-451. doi:10.1037/ 1040-3590.9.4.445

Gabbidon, S. L., \& Green, H. T. (2008). Race and crime (2nd ed.). Thousand Oaks, CA: Sage.

Gillum, T. L., Sun, C. J., \& Woods, A. B. (2009). Can a health clinic-based intervention increase safety in abused women? Results from a pilot study. Journal of Women's Health, 18, 1259-1264. doi:10.1089/ jwh.2008.1099

Goodman, L., Bennett, L., \& Dutton, M. A. (1999). Obstacles to victim's cooperation with the criminal prosecution of their abusers: The role of social support. Violence and Victims, 14, 427-444.

Goodman, L., \& Epstein, D. (2005). Refocusing on women: A new direction for policy and research on intimate partner violence. Journal of Interpersonal Violence, 20, 479-487. doi:10.1177/0886260504267838

Holroyd K. A., Labus J. S., \& Carlson, B. (2009). Moderation and mediation in the psychological and drug treatment of chronic tension-type headache: The role of disorder severity and psychiatric comorbidity. Pain, 143, 213-222. doi:10.1016/j.pain.2009.02.019

Johnson, D. M., Zlotnick, C., \& Perez, S. (2008). The relative contribution of abuse severity and PTSD severity on the psychiatric and social morbidity of battered women in shelters. Behavior Therapy, 39, 232241. doi:10.1016/j.beth.2007.08.003

Kendall, J., Pelucio, M. T., Casaletto, J., Thompson, K. P., Barnes, S., Petit, E., \& Aldrich, M. (2009). Impact of emergency department intimate partner violence intervention. Journal of Interpersonal Violence, 24, 280-306. doi:10.1177/0886260508316480

Klevens, J., Baker, C. K., Shelley, A., \& Ingram, E. M. (2008). Exploring the links between components of coordinated community responses and their impact on contact with intimate partner violence services. Violence Against Women, 14, 346-358. doi:10.1177/1077801207313968
Kraemer, H. C., Frank, E., \& Kupfer, D. J. (2006). Moderators of treatment outcomes: Clinical, research, and policy importance. Journal of the American Medical Association, 296, 1286-1289. doi:10.1001/ jama.296.10.1286

Kraemer, H., Wilson, G., Fairburn, C., \& Agras, W. (2002). Mediators and moderators of treatment effects in randomized clinical trials. Archives of General Psychiatry, 59, 877-883.

Krause, E. D., Kaltman, S., Goodman, L., \& Dutton, M. A. (2006). Role of distinct PTSD symptoms in intimate partner reabuse: A prospective study. Journal of Traumatic Stress, 19, 507-516. doi:10.1002/jts.20136

Krause, E. D., Kaltman, S., Goodman, L. A., \& Dutton, M. A. (2008). Avoidant coping and PTSD symptoms related to domestic violence exposure: A longitudinal study. Journal of Traumatic Stress, 21, 83-90. doi: $10.1002 /$ jts. 20288

Mechanic, M. B., Weaver, T. L., \& Resick, P. A. (2008). Mental health consequences of intimate partner abuse: A multidimensional assessment of four different forms of abuse. Violence Against Women, 14, 634-654. doi:10.1177/1077801208319283

Prochaska, J. O., \& DiClemente, C. C. (1983). Stages and processes of self-change for smoking: Toward an integrative model of change. Journal of Consulting and Clinical Psychology, 51, 390-395. doi:10.1037/ 0022-006X.51.3.390

Rennison, C. M., \& Welchans, S. (2000). Intimate partner violence. Washington, DC: Bureau of Justice Statistics, United States Department of Justice.

Robinson, A. L., \& Tregidga, J. (2007). The perceptions of high-risk victims of domestic violence to a coordinated community response in Cardiff, Wales. Violence Against Women, 13, 1130-1148. doi:10.1177/ 1077801207307797

Shurman, L. A., \& Rodriguez, C. M. (2006). Cognitive-affective predictors of women's readiness to end domestic violence. Journal of Interpersonal Violence, 21, 1417-1439. doi:10.1177/0886260506292993

Straus, M. A., Hamby, S. L., Boney-McCoy, S., \& Sugarman, D. B. (1996). The revised Conflict Tactics Scale (CTS2). Journal of Family Issues, 17, 283-316. doi:10.1177/019251396017003001

Sullivan, C. M., \& Bybee, D. I. (1999). Reducing violence using community-based advocacy for women with abusive partners. Journal of Consulting and Clinical Psychology, 67, 43-53. doi:10.1037/0022006X.67.1.43

Sullivan, C. M., Bybee, D. I., \& Allen, N. E. (2002). Findings from a community-based program for battered women and their children. Journal of Interpersonal Violence, 17, 915-936. doi:10.1177/ 0886260502017009001

Tjaden, P., \& Thoennes, N. (2000). Prevalence and consequences of male-to-female and female-to-male partner violence as measured by the National Violence Against Women Survey. Violence Against Women, 6, 142-161. doi:10.1177/10778010022181769

Received January 10, 2011

Revision received December 15, 2011

Accepted December 22, 2011 